\title{
REPRESENTAÇÕES DO COTIDIANO: A POPULAÇÃO EM DESFILE
}

Marilda Lopes Pinheiro Queluz*

Superposição de tempos, movimento constante, jogo paródico - a representação cômica parecia buscar outros domínios para falar da vida cotidiana e da vida privada brasileira, cujas fronteiras com a vida pública jamais se definiam, pois a superposição e a mistura pareciam constituir parte intrínseca das próprias formas de representação social (Elias Thomé Saliba).

\section{Resumo}

Este trabalho faz parte de uma pesquisa mais ampla sobre as representações da cidade e das experiências urbanas através da caricatura. O objetivo aqui, especificamente, é refletir sobre a diversidade cultural e as múltiplas visões que as revistas de humor curitibanas do início do século XX deixam entrever nas caracterizações das cenas cotidianas. Entre o preconceito e 0 estereótipo são construídos os vários olhares sobre a população, ressaltando a importância da presença dos negros e de sua participação no dia a dia da cidade, dando voz e corpo"a ẻssăs pešsoas "que normalmente ẻram ìnvisíveis na imprensa "oficial" ou tida como "séria". Se, por um lado, a ironia e a sátira reforçavam as diferenças e hierarquias sociais, por outro lado, rompiam com o discurso homogêneo e "branco" sobre Curitiba.

* Mestre em História pela Universidade Federal do Paraná e doutora em Comunicação e Semiótica pela Pontifícia Universidade Católica de São Paulo. Professora do Programa de Pós-Graduação em Tecnologia e do Departamento Acadêmico de Desenho Industrial da Universidade Tecnológica Federal do Paraná. (mqueluz@ig.com.br) 
Com o advento da República, o Brasil entrou no século XX preocupado em investir na modernização do país com a implantação de reformas urbanas e de inovações técnicas, tentando estabelecer um novo horizonte de imagens da cidade, uma nova visualidade.

No afã do esforço modernizador, as novas elites se empenharam em reduzir a complexa realidade social brasileira, singularizada pelas mazelas herdadas do colonialismo e da escravidão, ao ajustamento em conformidade com padrões abstratos de gestão social hauridos de modelos europeus ou norte-americanos. Fossem esses os modelos da missão civilizadora das culturas da Europa do Norte, do urbanismo científico, da opinião pública esclarecida e participativa ou da crença resignada na infalibilidade do progresso (SEVCENKO, 1998, p. 27).

Por tratar-se de uma modernização conservadora, deixando a grande maioria da população à margem dos benefícios, trouxe junto um certo desconforto, uma mistura de deslumbramento e desconfiança diante do inusitado, uma sensação de deslocamento nessa nova paisagem técnica que se impunha.

O sucesso das revistas de humor dessa época, recheadas de charges, talvez revele um pouco dessas novas percepções, dessa pluralidade de sentidos e significações, contrapondo-se, reforçando ou questionando, rompendo, enfim, com o discurso único e homogêneo das elites ${ }^{1}$.

Os caricaturistas, além de satirizarem os paradoxos presentes na idéia de progresso e modernidade, pluralizando os pontos de vista sobre a implantação de novos sistemas técnicos, voltaram-se para a heterogeneidade e complexidade da população que circula/transita pela cidade. Elegeram a rua, ou melhor, o limiar entre a rua e a casa, os salões, bares, teatros, como espaço privilegiado do olhar. As revistas eram, portanto, como passarelas por onde desfila quem está nas ruas, montadas como jogos de ver/deixarse ver/ocultar. Colocam em exposição os diferentes "atores sociais em suas diferentes funções" e os diversos regimes de visibilidade ou "situações de comunicação" entremeadas por vários tipos de discurso ${ }^{2}$.

1 Para esta pesquisa foram analisadas as seguintes revistas curitibanas: O Olho da Rua (1907-1911), A Carga (1907), A Rolha (1908) e A Bomba (1913).

2 Landowski discute os regimes de visibilidade e os modos de presença em A sociedade Refletida, $\mathrm{p}$. 85-90. 
Folhear suas páginas é um pouco como andar pelas ruas, transitar entre imigrantes, mulheres e homens, cidadãos, bandidos, boêmios, políticos, trabalhadores, observar uma outra forma de como o espaço urbano é ocupado e re-apropriado. A representação do povo dá-se como modos de presença. A cidade, seus padrões, tradições e contradições são desveladas não de forma parcial, uniforme, mas conflitantes, coexistindo, interagindo. A rua aparece como um espaço múltiplo, multifacetado, fragmentado. Uma festa em ritmos diversos. A rua, assim como a revista, insinua-se como um "mosaico de mútuas interferências" (PINHEIRO, 1994, p. 13).

No início do século XX, esses olhares se entrecruzam na tentativa dos poetas, escritores, pintores, desenhistas e caricaturistas de pensar a cidade e, por extensão, o próprio país através de suas ruas. Estas se apresentam como espaço pleno de significado, gerador de formas culturais inéditas, revelando a existência de uma população que se mantinha desconhecida aos olhos da República modernizadora. O submundo, a marginalidade, a boemia e as ruas constituem espaço expressivo para se pensar a modernidade brasileira...É nessa perspectiva que eles preferem falar da descoberta da cidade, de seus lugares e de seus tipos como ponto de partida para uma reflexão mais ampla (VELLOSO, 1996, p. 29).

Eles mostram interconexões e desigualdades que rompem com o desejo de uma sociedade homogênea, eminentemente branca, organizada, higienizada e disciplinarizada. Questionam a visão de poder de uma única classe, deixando entrever várias outras instâncias, onde o lugar do poder é constantemente deslocado entre as sutilezas tecidas no cotidiano.

Em contraponto aos "discursos normativos", as charges estão impregnadas de experiências outras, de trocas, memórias, vindas das rearticulações das práticas cotidianas dos diferentes grupos sociais e étnicos no novo espaço urbano. (PADILHA, 2001, p. 24-25).

A presença do imigrante ${ }^{3}$, ou dos negros nas imagens, por exemplo, se num primeiro momento mostra os preconceitos, acaba por ressaltar

3 Curitiba recebeu imigrantes com maior intensidade a partir da década de 1870. Em 1872 Curitiba tinha uma população de 12651 , em 1900 - 50124 e em 1910 - 60800. "A população imigrante, composta inicialmente por franceses e alemães, estes reimigrantes de Santa Catarina, foi acrescida 
sua importância e participação na sociedade. Ainda que marginalizados ou excluídos, estão fortemente representados no universo do humor gráfico. A caricatura, ao mesmo tempo em que destaca, também agrega, inserindo esses grupos sociais no dia-a-dia daquela população urbana.

As charges são perpassadas pelas ambigüidades do modernismo e da própria cultura. Ao criticar os novos tempos, querendo a preservação da tradição, do mundo conhecido, ressaltam o deslumbramento com 0 inesperado. Estão imbuídas de uma certa visão moralista, ao mesmo tempo em que desmontam as instituições e harmonias burguesas. Contêm uma certa mágoa nostálgica de outros tempos, na medida mesmo em que a ironizam. De alguma forma, "não se trata já tanto de perseguir com tristeza um objeto que falta e de sofrer uma ausência irremediável que metáforas regressivas recuperam ou que os mitos recobrem, mas de montagens contíguas que se rejubilam a idéia de fronteira, de estar fora-dentro, de morte" (PINHEIRO, 1994, p. 26-27).

Numa mesma imagem, os caricaturistas vão construindo/ desconstruindo valores. A discussão da sociedade é proposta nas fronteiras do espaço público e privado, com imagens do que se passa nas ruas, entrecruzada com a intimidade dos lares. O público e o privado contaminamse, são discutidos simultaneamente. Os caricaturistas/enunciadores rearticulam as questões cotidianas municipais para falar de questões particulares, pessoais. Multiplicam-se os matizes da sociedade, a partir do dia-a-dia, da experiência pessoal dos indivíduos.

Personagens importantes, políticos, pessoas comuns, desconhecidos, anônimos, marginalizados, são colocados lado a lado, dando voz e espaço a vários tipos de manifestações, sob óticas inusitadas. Essas justaposições e colagens apresentam-se quase como um contraponto às tentativas do Estado e de alguns setores da elite de organizar a sociedade, eliminando as diferenças, implantando técnicas de gestão pública e de controle da vida privada ${ }^{4}$.

por novos contingentes. Italianos, poloneses, alemães, e também alguns franceses e suíços passaram a resisir em colônias agrícolas, estabelecidas nos arredores da cidade."Maria Ignês de Boni, O espetáculo visto do alto, p. 7-11.

4 Para esse período em Curitiba ver a tese de Maria Ignês de Boni, O Espetáculo Visto do Alto. 
Por um lado, transparece nos discursos oficiais uma exaltação do trabalho e da produtividade, em oposição à malandragem e à vadiagem ${ }^{5}$.

Desejava-se, na verdade, que os homens livres internalizassem a noção de que o trabalho era um bem, um valor supremo regulador do pacto social...Disciplinarização do tempo e do espaço estritamente do trabalho - isto é, produção - pois a definição do homem de bem, do homem trabalhador, passa também pelo seu enquadramento em padrões de conduta familiar e social compatíveis com sua situação de indivíduo integrado à sociedade, à nação". Desta forma a vigilância "se completava, no cotidiano, pelo exercício da vigilância policial (CHALHOUB, 1986, p. 30).

Além disso, nessa época, tanto os bailes, os jogos, o carnaval e o álcool, quanto as manifestações de rua foram fortemente reprimidas, pois eram vistos como práticas condenáveis, dentro de uma lógica oficial onde predominava o discurso higienista, a exaltação da ciência moderna e do progresso, iniciava-se o culto à saúde e à beleza, a disciplinarização da sociedade e do corpo. ${ }^{6}$

As festividades populares apareciam na contramão desse processo civilizatório que implicava, entre outros, desafricanizar costumes e inibir manifestações de rua. Não é à toa que os batuques tenham sido colocados na ilegalidade em 1905, tendo desaparecido do carnaval baiano até os idos de 1930. (COSTA e SCHWARCZ, 2000, p. 92)

Por outro lado, as revistas de humor traziam quadros invertidos desses discursos, misturando-os com as práticas culturais. As charges fizeram leituras "avessas" dos códigos sócio-culturais, estabelecendo um ponto de vista divergente daquele dos indivíduos ditos "ajustados", sendo

5 No caso específico de Curitiba ver Erivan Karvat, A Sociedade do Trabalho. Curitiba: Editora Quatro Ventos.

6 Ver Sevcenko, p. 568-569 e Mônica Schpun, Beleza em Jogo. 
uma contrapartida aos supostos padrões de comportamento e condutas esperadas socialmente ${ }^{7}$.

O olhar sobre o outro também abrigava as diferenças étnicas. Em meio ao fortalecimento da ideologia do embranquecimento e de valorização do imigrante europeu, é significativa a constância dos negros nas charges ${ }^{8}$.

Contrariando o discurso oficial excludente, a presença dos negros é marcante. Mesmo que quase sempre caracterizados como subalternos, inferiores, impressionam pela freqüência com que aparecem nas páginas das revistas de humor pesquisadas. Fala-se com doses maiores ou menores de preconceito, mas fala-se muito. No discurso oficial os negros não estão presentes, não têm voz ou visibilidade, mas nas charges sim. Na construção dos olhares sobre a cidade, a presença dos negros nas ruas, no trabalho, nas transformações urbanas e da sociedade demonstra sua importância e participação ativa.

O difícil é superar a barreira imposta pelo filtro dos cronistas, dos sanitaristas, ideólogos da nova cidade; sobretudo porque a cidade moderna deveria ser entendida como uma cidade sem memória, sem as tradições e os laços que a uniam ao passado. Da mesma forma que o negro passou a ser visto como um ser a-histórico, assim também passaram a ser vistas suas manifestações, seus padrões de organização, suas velhas tradições, que remontavam ao passado étnico e da escravidão. Subjacente a essa visão do negro como um ser anômalo nos novos tempos, por suas tendências ao desregramento e à desorganização, existia uma idéia recorrente de tratá-lo como vazio de experiências e aprendizados; na visão de muitos, o negro ressurgia, assim, no período pós-abolição, como um ser vindo do nada, do vazio deixado pela escravidão e que, posteriormente, seria preenchido pelo conceito igualmente vago da marginalidade social.(WISSENBACH, 1998, p. 97-98)

7 Chalhoub cita Gilberto Velho: "A possibilidade da existência dessas leituras diferentes ou divergentes é garantida pelo próprio caráter desigual, contraditório e político de todo sistema sócio-cultural"

8 Para pensar a presença do negro e a construção dos discursos sobre o negro no Brasil, ver Lilia SCHWARCZ, Lilia. Retrato em Branco e Negro. São Paulo: Cia das Letras, 1987; SCHWARCZ, Lilia O Espetáculo das Raças. São Paulo: Cia das Letras, 1993. SKIDMORE, Thomas. Preto no Branco. Rio de Janeiro: Paz e Terra, 1973. AZEVEDO, Célia M. M. Onda negra, medo branco. Rio de Janeiro: Paz e Terra, 1987. 
As charges mostraram as distinções sociais, as hipocrisias, o espaço limitado de sua atuação, mas também a importância de sua presença, a impossibilidade de negar sua participação.

Para comemorar o dia da abolição, por exemplo, a capa de A Rolha (fig. 1) mostra o branco e o negro, colocados juntos, abraçados. Estabelecese um jogo de palavras entre o que é de bom tom e o tom de pele, uma distinção entre o que seria de bom tom: colocar tom sobre tom.

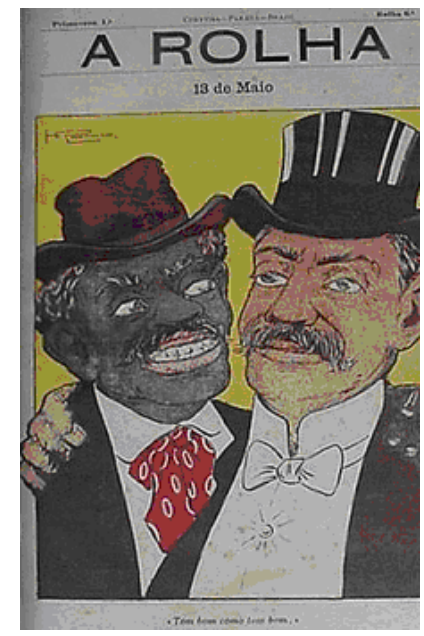

Fig. 1 - Herônio. A Rolha n.6 - 14/05/1908

" 13 de Maio"

“Tom bom como tom bom”

Mistura-se visualmente a homenagem e a crítica. Ressaltam-se as conquistas de espaço - nas ruas, na sociedade, na mídia, na capa da revista - valoriza-se a presença do negro, mas mostrando desigualdades, sem esconder a hierarquia, brincando, ironizando as diferenças. As roupas e expressões faciais marcam essas sutilezas. O branco está em primeiro plano, é maior, mais alto, com traje de gala - smoking, com brilho, sério, altivo. O negro com roupa mais simples, nem tão elegante, com destaque do vermelho da gravata e do chapéu, sorriso, olhando direto nos olhos do outro. 
$\mathrm{O}$ andar, a beleza e a sensualidade das mulheres negras também foram percebidos, sobressaindo-se aos olhares de quem estava nas ruas, marcando ritmo ao passo (fig.2). A atração da cor é traduzida na associação ao sabor da fruta, ao prazer de apreciar o que é bom.

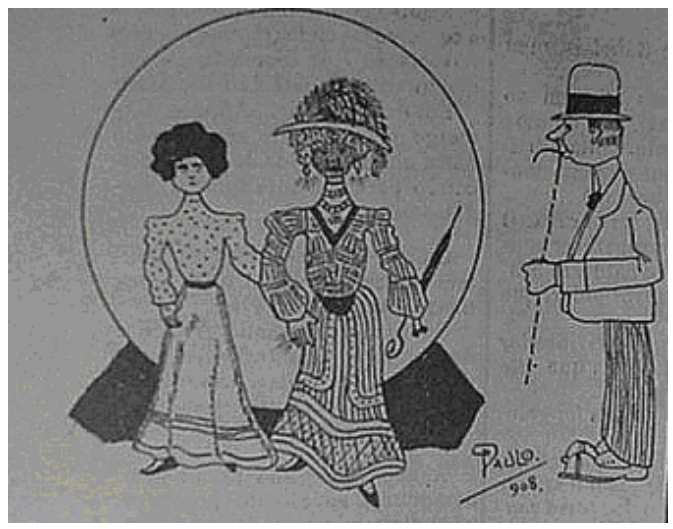

Fig.2 - Paulo. A Rolha n.6 - 14/05/1908

Ele - Aí morena cheirosa. Gostei de ver a elegância. Viva o 13 de maio de 88 que está produzindo esses deliciosos frutos!

A morena - É certo mesmo, "yôyô"! Maracujá quanto mais preto mais doce

A importância da aparência (fig.3), da moda, da roupa como aceitação social e igualdade em relação aos brancos também foi destacada como objeto de preocupação dos negros ${ }^{9}$. A brincadeira com as expressões inglesas abrasileiradas, o sotaque e a pronúncia, mostram a necessidade de

9 Maria Cristina C. Wissenbach mostra em seu estudo que a condição de livre era algo que os negros queriam ostentar e exibir, justamente através da posse e do uso de objetos que lhes eram negados quando eram escravos. Ela cita o relato de L. Gaffre sobre a importância que o sapato assumiu para essa população. "A escravidão, com efeito, não lhes dava o direito de se calçar, e parecia claro como o dia a essas bravas gentes que iriam se equiparar aos senhores de ontem usando, como eles, botas e borzeguins. O primeiro gesto da liberdade foi então aprisionar os pés nas fôrmas escolhidas..." Mas como não estavam acostumados, "passavam felizes e orgulhosos, com uma postura altiva, descalços, mas todos levando um par de sapatos por vezes à mão, como um porta-jóias valioso, ou por outras a tiracolo, como as bolsas vacilantes da última moda mundana."p. 54 
ser moderno não só no visual, mas também na fala. A liberdade também se conquistava pelas aparências. Ser livre e parecer moderno se traduzia pela entonação, pelos gestos, pelo visual.

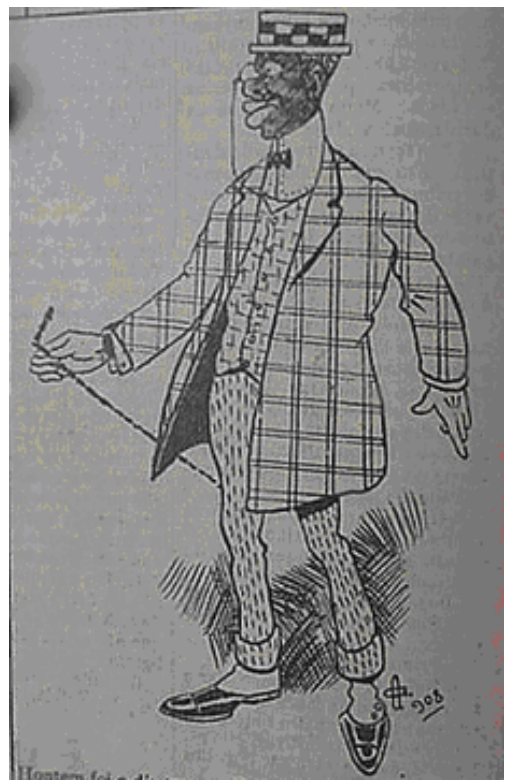

Fig. 3 - O.G. A Rolha n. 6 - 14/05/1908

Ontem foi o dia treze. Foi dizê a sinhazinha:

Nego assim upitudarte.

Nego hoje ta tudo esmarte

O desejo de vestir-se como os brancos e de apropriar-se dos espaços freqüentados pelos brancos é satirizado na fig.4. A ironia dos traços e dos diálogos sublinha não apenas os erros da fala, o desnível social, mas a falta de acesso e participação na sociedade. São livres, estão bem vestidos, mas como estranhos, quase caveiras, tortos, dançantes. O grotesco do desenho parece falar da indignação dos negros que não tinham muito a comemorar no "dia deles". 


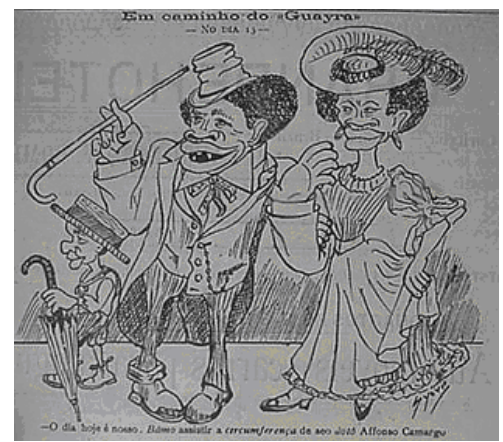

Fig. 4 - Sylvio. A Rolha n. 6 - 14/05/1908

"Em caminho do Guayra"

- O dia hoje é nosso. Bâmo assisti a circumferença do seo doto Affonso Camargo

Nas charges, entre as atividades profissionais ligadas aos negros é recorrente a imagem do guarda, pertencente ao regimento de segurança (fig.5, 6, 7). Ao colocar em cheque a violência urbana e a impunidade dos "gatunos", as charges dão visibilidade ao negro policial, quase sempre vítima de maus tratos, da própria ignorância, da péssima remuneração e da falta de chances na carreira e na sociedade. Nos jogos de palavras, nas brincadeiras com a cor, um toque de "nonsense" constrói, pela ambigüidade, a presença negra.

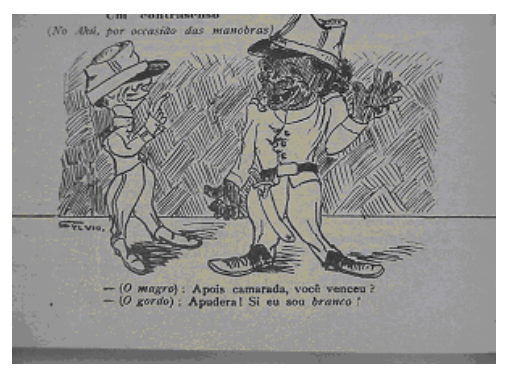

Fig.5 - Sylvio. O Olho da Rua n.3, 1907.

"Um contra-senso"

(no Ahu por ocasião das manobras)

(o magro) Apois camarada, você venceu?

(o gordo) Apudera! Si sou branco! 


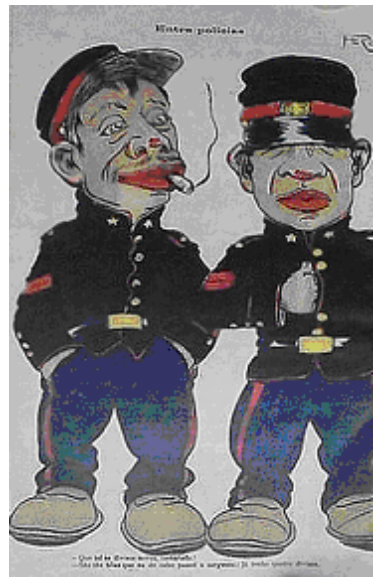

Fig.6 - Herônio. A Carga n. 8, 21/12/1907.

- Que tal nossas divisas novas?

- São tão boas que eu de cabo passei a sargento...já tenho 4 divisas

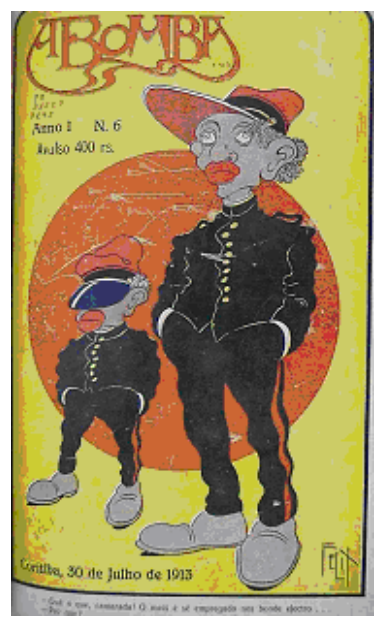

Fig.7 - Felix. A Bomba n.6, 30/07/1913

- Quá o que, camarada! O meio é sê empregado nos bonde electro... - Pro que?

- Pro que antão semo nóis memo que peguemo nos arame... 
Ao zombar do espaço almejado pelo cidadão e do espaço que realmente ocupa na sociedade, as caricaturas deixam entrever as feridas, as mazelas da escravidão, e ao mesmo tempo dão voz, criam/integram novos espaços. Mostram as formas de exclusão e re-apropriação simultâneas dos espaços públicos e privados da cidade. Todos esses personagens, entre encontros e desencontros, entre conversas e reflexões solitárias, fazem explodir nas páginas das revistas a heterogeneidade social, a diversidade cultural e, sobretudo, as interferências das pessoas na cidade, as interações cotidianas.

\section{REFERÊNCIAS}

BONI, Maria Ignês de. 0 espetáculo visto do alto. Curitiba: Ed. Aos Quatro Ventos, 1998.

CHALHOUB, Sidney. Trabalho, Lar e Botequim. O cotidiano dos trabalhadores no Rio de Janeiro da Belle Époque. São Paulo: Brasiliense, 1986

COSTA, Ângela Marques da e SCHWARCZ, Lilia M. 1890-1914 - No tempo das certezas. São Paulo: Companhia das Letras, 2000.

LANDOWSKI, Eric. A sociedade Refletida. Ensaios de sociossemiótica. Trad. Por Eduardo Brandão. São Paulo: EDUC/Pontes, 1992

PADILHA, Márcia. A cidade como espetáculo. Publicidade e vida urbana na São Paulo dos anos 20. São Paulo: Annablume, 2001

PINHEIRO, Amalio. Aquém da Identidade e da Oposição. Formas na cultura mestiça. Piracicaba: Unimep, 1994

SEVCENKO, N. org. História da Vida Privada no Brasil. República: da Belle Époque à Era do Rádio. São Paulo: Companhia das Letras, 1998 
SALIBA, Elias Thomé. A dimensão cômica da vida privada na República. In SEVCENKO, N. org. História da Vida Privada no Brasil. República: da Belle Époque à Era do Rádio. São Paulo: Companhia das Letras, 1998

VELloSO, Mônica Pimenta. Modernismo no Rio de Janeiro. Rio de Janeiro: Editora Fundação Getúlio Vargas, 1996

WISSENBACH, Maria Cristina Cortez. Da escravidão à liberdade: dimensões de uma privacidade possível. In SEVCENKO, N. org. História da Vida Privada no Brasil. República: da Belle Époque à Era do Rádio. São Paulo: Companhia das Letras, 1998 
